\title{
Middle Hope
}

Dr Joe Gerlach, School of Geography and the Environment, University of Oxford and Keble College joe.gerlach@ouce.ox.ac.uk

If used prior to publication, please cite as: Gerlach, J. 2016 Middle Hope. Cultural Geographies. (in press)

\begin{abstract}
How does one hope? In this short essay, I narrate moments from time spent at Middle Hope, a small coastal inlet of the Severn Estuary, England. These moments aim to offer, hesitantly, brief respite from certain liberal narratives that rely upon the promulgation of 'hope' as a reasonable societal disposition with which to face planetary transformation. I suggest, instead, a turn to ambivalence and melancholy.
\end{abstract}

\section{Key words}

Hope, Severn, melancholy, hiraeth, Spinoza

I.

Middle Hope; a small coastal inlet of Somerset, south-western England, carved into a promontory that juts out to the Severn Estuary. Or, thought differently for a second, 'in the middle of hope'; a mischievously Latourian turn of phrase, the location, perhaps, of geographers and geographies long mired in the prospect and puzzle of hope.' From the calculated - and calculating - imposition of indexical happiness upon populations by certain nation states ${ }^{2}$ to the intellectual conjecture of grief and reconciliation invested in narratives concerning the Anthropocene, ${ }^{3}$ hope continues (against hope) to exercise contemporary cultural geographies. ${ }^{4}$ Hope's appropriation by state, scholar and activist ${ }^{5}$ as the affect-of-choice is peculiar given its conceptual indeterminacy. The 'Anthropocene', for example, when finally and formally categorised as a geological epoch, will be identified, in part, by its stratigraphic signature. ${ }^{6}$ Concomitantly, its forthcoming pronouncement is likely to be accompanied by the feeling that something untoward, something unseemly, something human has happened, and that worse is afoot. Yet hope, with little rationale has emerged as a prominent affective motif with which to engage with epochal environmental concerns. Likewise, whilst conceptual taxonomies of hope presently counter liberal encodings of an associated but unrelated 'optimism', what it means to hope, or rather the question of 'how does one hope?' remains vexing.'

I pose this existential question in the context of what one might, in hope of a sympathetic reader, and somewhat tongue-in-cheek, label 'fieldwork'. Or more specifically, the question arises in the moments, encounters and witnessing in a day spent in and around Middle Hope. Elsewhere in cultural and political geography, fragments of south-west England have animated empirical spaces in which geographers have questioned the extent to which the sensibilities and specificities of place can be made to speak to phenomenal, embodied and geopolitical encounters in landscape ${ }^{8}$. In attempting to continue this recent experimental regional geography of 
south-west England, I offer a modest critique of hope from a stretch of the coastline where the water shifts from an Atlantic blue to a turbid, Bristolian brown.

II.

Middle Hope; its etymology itself mired in the middled, muddle of old Middle English. 'Hope', in this story, denotes a sunken inlet, or in parts of northern England, a valley. Just west of the inlet the official line where estuary and channel merge, where the River Severn gives ways to the Bristol Channel. A cloud's shadow darkens the already murky water. The tide, when it peaks and then dissipates near to the Autumnal equinox, floods and scours the muddy estuarine bed. 'Treacherous mud', warns a nearby sign. This is no place for a swim. Rocky outcrops are left exposed by the receding tide; limpets (patella vulgata) cling relentlessly to jagged rocks. The limpet strives - its conatus - towards an anticipation of the tide's return.

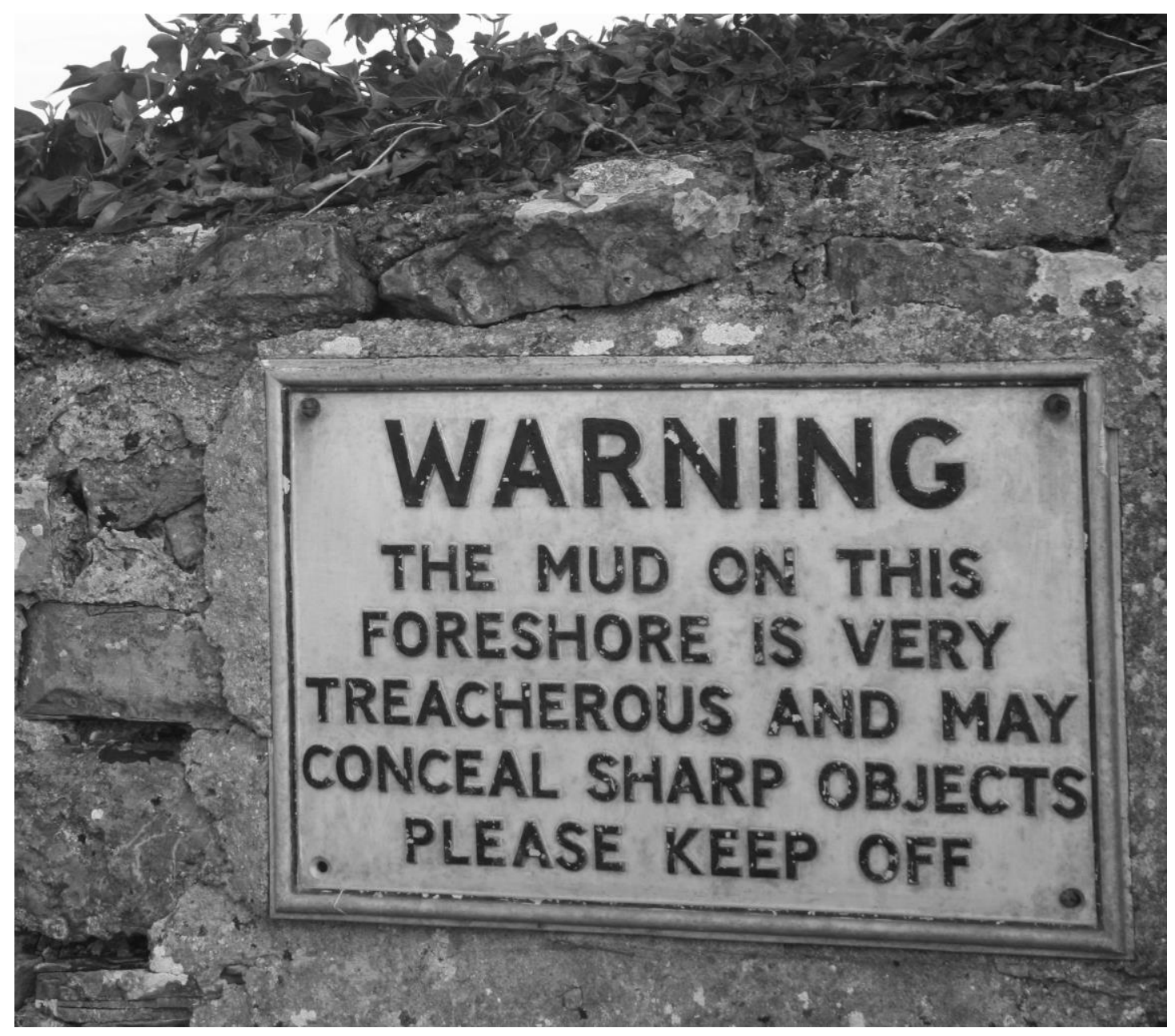

Fig. I Treacherous Mud (Photograph by Author)

Middle Hope is a geological extension of England's Mendip Hills that course eastwest across Somerset. Carboniferous, Black Rock Limestone dominates the local geology, yet Middle Hope is the site of seemingly incongruous volcanic basalt deposits. Middle Hope also marks one of the rare sites of Pleistocene deposits in this part of Britain; residues that stratigraphically lie at odds with the otherwise 
Holocene legacy of the inlet'. Fossils are etched into the grey rocks; anemones and flattened jellyfish abound. Jellyfish; "we cannot touch them without inviting distress", writes Elizabeth Johnson. ${ }^{10}$ Looking, for me, is anxiety enough. The fossilised jellyfish of Middle Hope are a stinging reminder of their pre-eminence as durable beings; simultaneously primordial entities and virtual signatures of the coming Anthropocene. As Johnson goes on to suggest, jellyfish give rise to paradoxical concerns; one, that they signal apocalyptic ecological degradation, and two, that they offer significant hope in the advancement of biomedicine. Such a paradox neatly points to an affective ambivalence in contemporary politics, perhaps not unique to the Anthropocene, but one which oscillates between hope and anxiety. Encountering fossilised jellyfish also raises, albeit perversely, the question of non-human affects. Do, against human intuitions, jellyfish hope? Did jellyfish ever hope of the epochal durability they have both survived and help generate?

Such questions undoubtedly incite incredulity, not least because they are predicated upon assumptions of an autonomous, non-human sentience. Yet at this site of Middle Hope, might not one question, what is more ludicrous - that jellyfish ponder hope, or that retrofitted geological epochs, as in the case of the Anthropocene, should give space for hope, however monumental or tentative in register? Regarding the former, we cannot know. Regarding the latter, a key issue lies in a political overcoding of geology undertaken in the name of the Anthropocene, provoked, in part, by the "geosciences attempt to move above ground"." It is in this fervent intellectualpolitical complex that matters of hope and grief become entangled. Yet returning to the windswept shore of Somerset, how does one hope from Middle Hope? There is nothing automatic about hope here; no epochal fissures that tell of hope, no landscaped manifesto for hopefulness. Perhaps the problem is not so much with 'hope' itself as it is an incipient worry about an assumed, taken-for-granted tendencies towards hope and hopefulness.

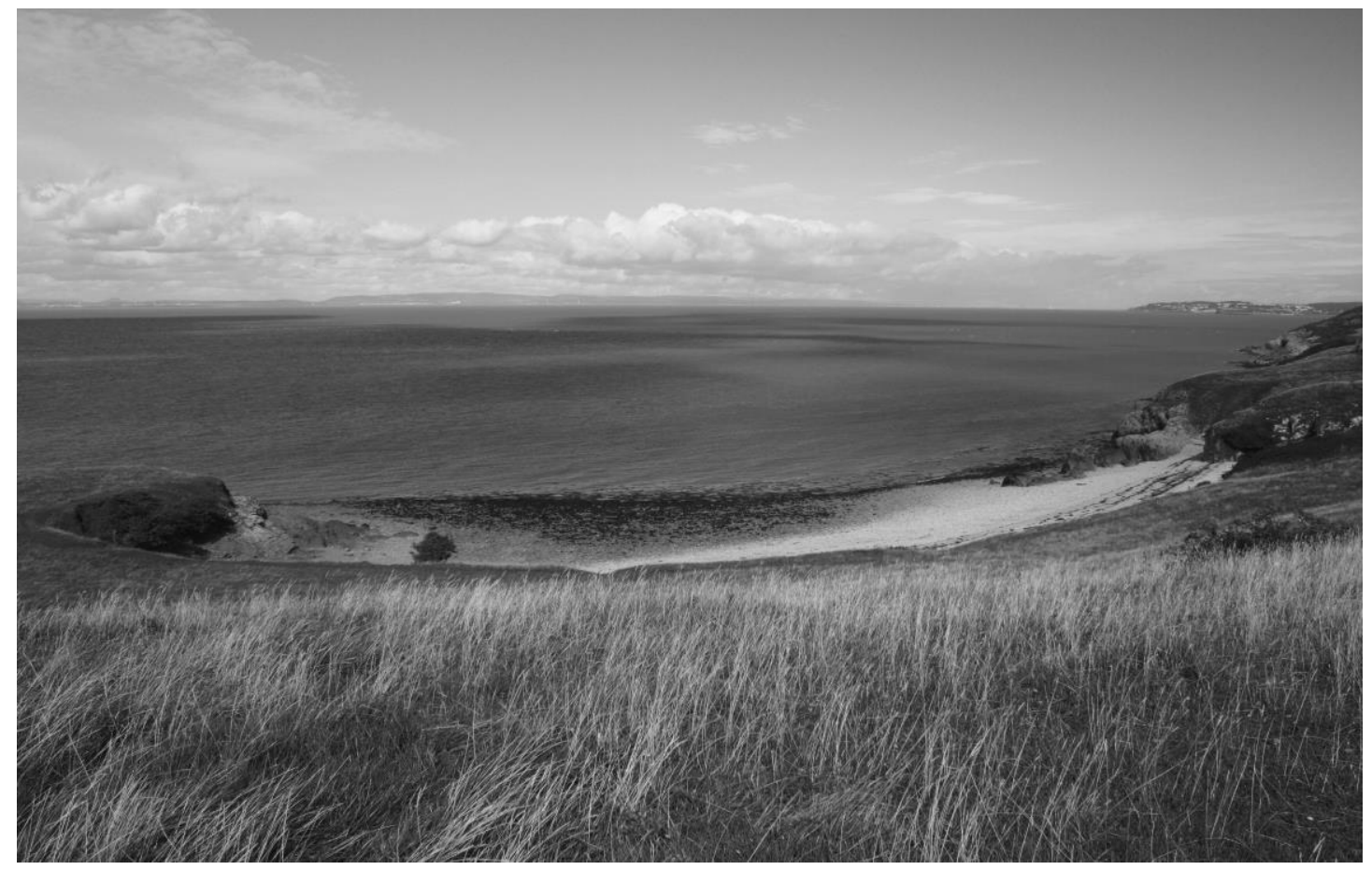

Fig. 2 Middle Hope, Somerset, UK (Photography by Author) 
III.

Middle Hope is both a Site of Special Scientific Interest, and also titled as National Trust land. ${ }^{12}$ It is trust - writes Ben Anderson - an enrolment into relations of trust, and a cultivation of an ethos of care that is central to the act and encounter of hoping. ${ }^{13}$ To be sure, this is a productive basis for hope, yet at Middle Hope at least, it appears that trust - institutional or otherwise - is as precarious and as ambivalent as hope itself. Walking through the sandy grasses on the approach to Middle Hope's inlet I take note of, and occasionally photograph the following; thistles, bramble, an abandoned instant barbecue, cow-pats, blackthorn (species: prunus spinosa). Spinoza (species: Baruch/Benedict de) is often turned to when considering hope, or as a precursor to broader philosophies of affirmation. Strange moves, perhaps, given that he has remarkably little to say on hope, an affect he holds in intractable relation to fear. As Terry Eagleton concludes, "hope for Spinoza is always mixed with fear precisely because its object is obscure. ${ }^{14}$ Ironically, then, more credence should be paid to Spinoza's lack of detail, or reticence, on hope, precisely because he was otherwise assiduously clear on other passions and affects.

In the middle of Middle Hope, it is still and quiet, unperturbed by the unpredictability of English weather. The past-their-best sandwiches languishing in my backpack fulfilling the parody of a day spent by the British seaside. To paraphrase Robert Burton, it plays into something like geography of melancholy. ${ }^{15}$ Standing on the cliff's edge, I look left to right, swayed a little by blustery winds. Bracing, but no haze commanding views, so to speak. Peering out to the south-west some twenty miles, I can see the two imposing oblongs of Hinkley Point A Nuclear Power station sat across the bay. Memories flash of a school visit to the reactor hall followed by a quick paddle in the disconcertingly warm waters surrounding the complex, its cooling system reliant on estuarine water which would be returned to the sea three degrees Celsius higher. For a Brit, that's approaching sub-tropical conditions. Turning to the right, looking north, the town of Clevedon lies ten-miles adrift from Middle Hope. Closer still, mere yards away, a visible but off-the-map weapons development and testing site. ${ }^{16}$ Middle Hope, then, as hope sits globally, rests precariously between fractious geopolitical-energy interests upended in the tumult of 'Brexit'" , and the sub-contracted, concealed machinery of state-violence. This is not hope; this is, at a stretch, the melancholy of the security-military complex. Middle Hope is the middling foil of a landscape held in national trust, yet kettled, geopolitically, between atomic fission and arms manufacture.

I look out to the water, to the Severn estuary; it's altogether more soothing for the mind, momentarily so. Whilst it is something of a tall-tale, the term 'Severn' is the Anglicised form of the Welsh word 'Hafren'. In turn this word is derived from the name of a legendary princess who drowned in these very same waters, at the hands of her own mother, no less. Every enunciation of the river - every rolling-in of the tide, if read away from hope, is a recantation of maternal filicide; one that echoes for the countless times people have ended their lives in this stretch of excoriating river. Seaweed, rusty scraps of sheet metal, the durability of washed-up Coke bottles, random bits of litter that don't bear attempts at identification. All gifts from obliging oceanic gyres; material remains that call to mind, or are themselves waste, decomposition and death. Hardly nascent grounds for hope. In the middle of Middle 
Hope, might it not be more appropriate to accommodate feelings of ambivalence, irony and melancholy?

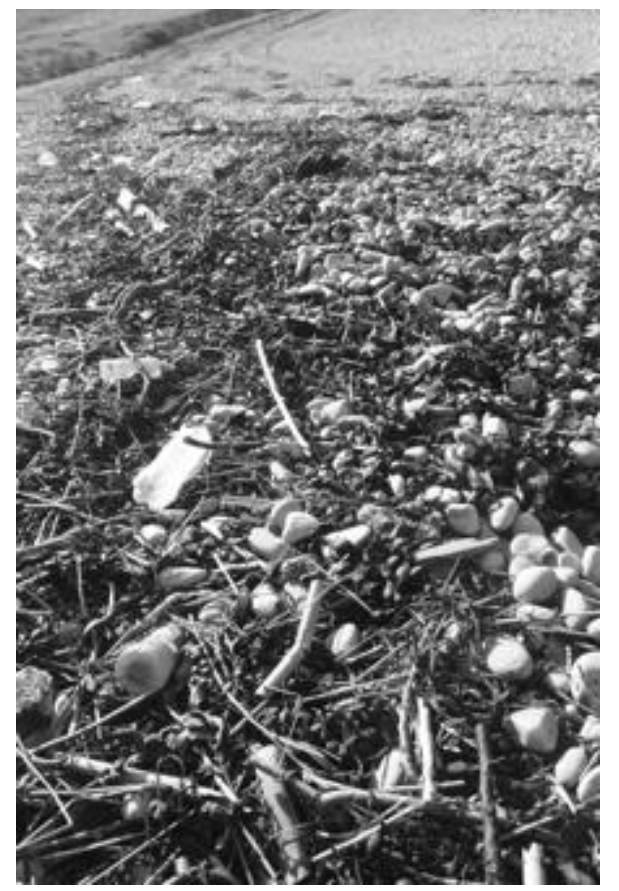

Fig. 3 High Tide Line (Photograph by Author)

Across the estuary, and squinting considerably, I just make out the coal hill valleys of south Wales. They are industrially sized reminders of a different stratigraphic seam shut down in the 1970s and 1980s with vindictive, Thatcherite intent. Former miners living across the water used to have geologic lives too, the substrate of coal-soot often found coursing in their blood. Minor-miner-bodies surfacing for a few hours at a time, drills' decibels still ringing in the ear, laboured by the cruel optimism of excavation. Occasionally, a black silt laps at the high tide-line of Middle Hope. Truth be told, I don't know what it is, l've not bothered to find out, though in walks past, my grandparents would tell me it was coal deposits that had washed up from Wales. Indeed, anything remotely suspect arriving on English shores from that direction, no matter bad weather, oil slicks or otherwise, was often - half-jokingly - attributed to the Welsh. It's an imaginative and clichéd geography of blame, that much like 'hope', helps offset responsibility for all manner of geographical quandaries.

One idea, one word, that has not washed up on the shores of Middle Hope from across the Severn is 'hiraeth', a Welsh term with no cognate in English. Pejoratively, hiraeth has been figured as homesickness. Read less acerbically, it pertains to an idea of longing, however abstract such longing might be. Crucially, hiraeth entails longing for longing's sake. There is no space for hope in this mode of longing. It could appear at first blush that hiraeth is a Welsh take on melancholy, itself derided by Spinoza for diminishing the capacity of a body to act. ${ }^{18}$ However, hiraeth augments such capacities by attuning bodies and minds to a future or futurity that may never arrive. It relies not on coded relations of trust, and persists in the face of what Spinoza would call 'sad passions'. Hiraeth, not hope, thrives as much on negation as it does affirmation. It is a proficient and productive melancholy. More importantly, it does 
not rely upon a national trust of relations in an ill-defined societal hope to nowhere. ${ }^{19}$

IV.

"The love that has no hope of being loved"20

Admittedly, all such thoughts go a long way to spoil what might otherwise be a perfectly pleasant walk. Nonetheless, to walk in and around Middle Hope helped to examine a little of what it is to live in the middle of hope; the political presage of an uncertain geological-geopolitical epoch. Such quick recourse to 'hope' in contemporary, liberal political narratives, including in their mildly agonistic forms, can be stifling, not least because it feels like there exists a duty to be hopeful, even in the face of the social-mental-ecological disasters that psychoanalyst Felix Guattari once wrote of. ${ }^{21}$ Middle Hope is not just the extent of a geologically peculiar promontory, nor hope the conceptual extent of liberalism - it is also the accretion of silt, atoms, weapons and indeed a sense of longing, however painful. The imagining of how one might hope in such a landscape is hampered by the inadequacy of the idea of hope, to borrow terminology from Spinoza once more. Hope's inadequacy lies in both the muddle of affects it produces and in its ambivalence, needing always to be tethered to fear. We could, indeed, ignore Spinoza's ambivalence surrounding hope, or we could, as Guattari demands, face up to such ambivalence. That is to say, Guattari identified a collective logic of 'desiring ambivalence' amongst humanity; a logic in which recourse to simple affects needs to be eliminated through acts, however simple or mundane, of untethering from the disciplinary shackles of hope. Jorge Luis Borges writes, above, in relation to Spinoza's philosophy, of an unrequited love for his work; similarly, in the spaces of Middle Hope, one finds a lament for hope itself the hope that has no hope of being hoped.

\section{Funding}

This work received no specific grant from any funding agency in the public, commercial, or not-for-profit sectors.

\section{Acknowledgements}

I am grateful to the Editors for their incisive feedback.

\section{Notes}

\footnotetext{
' Following Bruno Latour's insistence to 'always start in the middle of things' in B. Latour, Reassembling the Social: an Introduction to Actor-Network Theory (Oxford University Press, 2005), Pp25.

${ }^{2}$ See G. Brulé and R. Veenhoven 'Geography of Happiness: configurations of affective and cognitive appraisal of life across nations'. International Journal of Happiness and Development 2 (2015), pp I0I 117.

${ }^{3}$ See, for example, L. Head, Hope and Grief in the Anthropocene: Re-conceptualising Human-Nature Relations (Routledge, London., 2016).

${ }^{4}$ See, for example, Ben Anderson's excellent disquisition on Ernst Bloch in B. Anderson

'"Transcending without Transcendence": Utopianism and an Ethos of Hope'. Antipode 38 (2006),
} 
Pp69I-710. See also, B. Anderson, Encountering Affect: Capacities, Apparatuses, Conditions (Ashgate, Farnham., 2014) and B. Anderson 'Becoming and being hopeful: towards a theory of affect'.

Environment and Planning D: Society and Space 24 (2006) pp733-752. Elsewhere, see, R. Coleman \& D. Ferreday eds. Hope and Feminist Theory (Routledge, London., 20II) and N. Castree, P.

Chatterton, N. Heynen, W.Larner, M.Wright eds. The Point is to Change it: Geographies of Hope and Survival in an Age of Crisis (Wiley-Blackwell, Chichester., 2010).

${ }^{5}$ See, for example, F. Watkins 'Hope and Burnout in the Anthropocene' (2016)

http://www.commondreams.org/views/2016/05/26/hope-and-burnout-anthropocene

${ }^{6}$ This decision is, at the time of writing, pending approval by the International Commission on

Stratigraphy.

${ }^{7}$ See, for example, L. Berlant, Cruel Optimism (Duke University Press, Durham NC., 20I I).

${ }^{8}$ See, for example, the conversation between John Wylie and Mark Blacksell in J.Wylie 'A single day's walking: narrating self and landscape on the South West Coast Path'. Transactions of the Institute of British Geographers 30 (2005) pp234-247 and M. Blacksell 'A walk on the South West Coast Path: a view from the Other side'. Transactions of the Institute of British Geographers 30 (2005) 5I8-20. See also J. Sidaway 'Shadows on the Path: Negotiating Geopolitics on an Urban Section of Britain's South West Coast Path'. Environment and Planning D: Society and Space 27 (2009) 1091-1 I 16.

${ }^{9}$ See S. ApSimon and D. Donovan 'Marine Pleistocene deposits in the Vale of Gordano, Somerset'. UBSS Proceedings 7 (1956) pp. I30-I36 and TJ. Faulkner 'The early Carboniferous (Courceyan) Middle Hope volcanics of Weston-super-Mare: development and demise of an offshore volcanic high'. Proceedings of the Geologists' Association 100 (1989), pp93-106.

${ }^{10}$ E. Johnson 'Governing Jellyfish: Eco-Security and Planetary 'Life' in the Anthropocene' in Braverman, I. ed. Animals, Biopolitics, Law: Lively Legalities (Routledge, Abingdon, 2016).

" A. Barry 'The Impacts of the Anthropocene'. Presentation delivered at 'Society in the Anthropocene' Conference, Cabot Institute, University of Bristol, June 2013.

12 The National Trust, established in 1895 is a conservation charity whose aim is to preserve and protect historic places in England, Wales and Northern Ireland. It is one of the largest private landowners in the United Kingdom.

${ }^{13}$ B. Anderson (2006), 704.

14 T. Eagleton, Hope without Optimism (University of Virginia Press, 2015), pp78.

${ }^{15}$ See AS Chapple 'Robert Burton's Geography of Melancholy'. Studies in English Literature 33 (1993) PP99-130.

${ }^{16}$ The site is run by British defence multinational, Qinetiq.

17 The contentious planned re-development of the Hinkley Point Nuclear Power Station in Somerset is, at the time of writing, currently on hold owing, in part, to the political fallout of the United Kingdom's June 2016 vote to withdraw from the European Union, colloquially termed 'Brexit'. ${ }^{18}$ B. Spinoza, The Ethics (Penguin, London., 1996 [1677])

${ }^{19}$ See D. Polk, A Book called Hiraeth: a longing for Wales (Alun Books, 1983).

${ }^{20} \mathrm{JL}$ Borges, 'Baruch Spinoza' La moneda de hierro (Emece, Buenos Aires, 1976) ppI I7.

${ }^{21}$ F. Guattari, The Three Ecologies (Continuum, London., 2000). 